\title{
Abduction - the Context of Discovery + Underdetermination = Inference to the Best Explanation
}

\section{Mousa Mohammadian}

\begin{abstract}
The relationship between Peircean abduction and the modern notion of Inference to the Best Explanation (IBE) is a matter of dispute. Some philosophers, such as Harman (1965) and Lipton (1991, p. 58, 2004, p. 56), claim that abduction and IBE are virtually the same. Others, however, hold that they are quite different (Hintikka 1998; Minnameier 2004) and there is no link between them (Campos 2009). In this paper, I argue that neither of these views is correct. I show that abduction and IBE have important similarities as well as differences. Moreover, by bringing a historical perspective to the study of the relationship between abduction and $\mathrm{IBE}$ - a perspective that is lacking in the literature-I show that their differences can be well understood in terms of two historic developments in the history of philosophy of science: first, Reichenbach's distinction between the context of discovery and the context of justification-and the consequent jettisoning of the context of discovery from philosophy of science-and second, underdetermination of theory by data.
\end{abstract}

\section{Keywords:}

Abduction, Charles Sanders Peirce, Inference to the Best Explanation, Peter Lipton, the Context of Discovery, Underdetermination

\section{Introduction}

The relationship between Peircean abduction (henceforth simply "abduction") and the modern notion of Inference to the Best Explanation (IBE) is a subject of profound disagreement. Some philosophers have been assuming, usually without argument, that abduction and IBE are virtually identical. The first section of Harman's "The Inference to the Best Explanation” (1965) begins as follows: "The inference to the best explanation" corresponds approximately with what others have called "abduction," "the method of hypothesis," [and] "hypothetic inference"..." (1965, pp. 88-89). Since on different occasions Peirce calls abductive inference "abduction," "hypothesis," and 
"hypothetic inference" (as well as "retroduction" $(8.228,1910)^{1}$ and "presumption" $(2.774,1902)$ ), the passage suggests that abduction and IBE are almost identical. A very similar approach can be seen in the philosophy of science literature too. Ian Hacking (1983, p. 52), for instance, writes: "The idea of 'inference to the best explanation' is quite old. C.S. Peirce (1839-1914) called it the method of hypothesis, or abduction.” A more or less similar view can also be found in Barnes (1995, p. 251) and more interestingly_at least for the purpose of this paper-Lipton (1991, p. 58, 2004, p. 56). ${ }^{2}$

However, more and more philosophers are distancing themselves from the idea that abduction and IBE are the same. Jaakko Hintikka, for instance, claims that since abduction is "a hypothesis-forming operation" (1998, p. 510) and "the only way of introducing new hypothesis into inquiry" (1998, p. 511), it is inherently ampliative. Yet,

explaining a certain explanandum $\mathrm{E}$ is to derive it from an assumed background theory $\mathrm{T}$ plus a number of contingent truths $A$ which are relative to $E$ and which have to be found in order for an attempt to explain E to succeed. An explainer's job description is thus twofold: on the one hand to find the auxiliary facts $\mathrm{A}$ and on the other hand to deduce the explanandum from them together with the background theory T. (Hintikka 1998, p. 507; my emphasis)

Now, since neither finding auxiliary facts nor deducing the explanandum from theory and auxiliary facts is ampliative, explanation is not abductive. Thus, IBE is inherently different from abduction. Similar to Hintikka — and to some extent following him-Minnameier (2004) and McKaughan (2008) claim that abduction and IBE are completely different. Campos (2009) and McAuliffe (2015) take one step further and claim that not only are abduction and IBE completely different, but also there is no link between them and abduction should not even be considered as a conceptual predecessor to IBE.

In this paper, I argue that neither of these extreme views is correct. Rather, abduction and IBE have important similarities as well as differences. Moreover, by bringing a historical perspective to the study of the relationship between abduction and IBE- a perspective that all the above mentioned works lack-I show that their differences can be well understood in terms of two historic developments in the history of philosophy of science: first, Reichenbach's distinction between the

\footnotetext{
${ }^{1}$ References to Collected Papers of Charles Sanders Peirce (Peirce 1931-1935; 1958) are of the form (volume number. paragraph number, date).

${ }^{2}$ For an even longer list of philosophical works in which abduction and IBE are taken to be virtually identical, see (McAuliffe 2015).
} 
context of discovery and the context of justification (DJ distinction)-and the consequent jettisoning of the context of discovery from philosophy of science-and second, underdetermination of theory by data.

The structure of the paper is as follows. Section 2 describes Peirce's mature theory of abduction. As I shall show, abduction is a two-phase process of generating explanatory hypotheses to explain a given phenomenon and ranking these hypotheses in order to adopt the most pursuitworthy hypothesis for further considerations (e.g., empirical tests). In Section 3, I discuss IBE. In particular, I focus on Lipton's account of IBE as introduced in his Inference to the Best Explanation (2004). Finally, in Section 4, I examine the similarities and differences of Peircean abduction and Lipton's account of IBE and show how their major differences can be understood in terms of DJ distinction and underdetermination of theory by data.

\section{Peirce's Theory of Abduction}

Answering "What is Peircean abduction?" is not easy. It took about four decades for Peirce to fully develop his theory of abduction and sometimes he was very critical of his own previous views (2.102, 1902). With two caveats, here I am going to provide a relatively comprehensive description of Peirce's theory of abduction for our current purpose. First, I exclusively focus on Peirce's mature theory of abduction. Based on a fundamental change in Peirce's approach towards abduction in the late 1890s, Fann (1970) divides his theory of abduction to the early theory from 1859 to 1890 and the later theory from 1890 to 1914 . In the first period, Peirce's major preoccupation is to find the logical form of abduction. He suggests several forms which are actually "different permutations of the premisses and conclusions of a syllogism" (Levi 1995, p. 72). Yet, in 1902, in a retrospective reflection on his early theory, he admits a "capital error" he had committed because he "was too much taken up in considering syllogistic forms" which he "made more fundamental than they really are" $(2.102,1902)$.

In his later theory, however, the logical form of abduction is not a matter of import anymore. Throughout the period of his latter theory, he suggests a logical form for abduction only once. In his Harvard Lectures on Pragmatism (1903), Peirce states that abduction has "a definite logical form":

The surprising fact, $\mathrm{C}$, is observed;

But if $\mathrm{A}$ were true, $\mathrm{C}$ would be a matter of course,

Hence, there is reason to suspect that $A$ is true. $(5.189,1903)$ 
But later, in an important letter to Paul Carus, once again he suggests that abduction cannot be understood formally. After describing his discovery of trichotomy, that is, of three fundamentally different types of reasoning that include abduction, deduction, and induction, Peirce adds:

The general body of logicians had also at all times come very near recognizing the trichotomy. They only failed to do so by having so narrow and formalistic a conception of inference (as necessarily having formulated judgments for its premises) that they did not recognize Hypothesis (or, as I now term it, retroduction) as an inference. (8.228, 1910; original emphasis)

In Peirce's mature theory, as we shall see, abduction is understood as the first stage of scientific inquiry and not a merely formal inference.

Second, there are three main interpretations of Peirce's mature theory of abduction in the literature. According to the first interpretation that can be called the Generative Interpretation, abduction is all about forming explanatory hypotheses, or hypotheses-generation. ${ }^{3}$ According to the second interpretation that can be called the Pursuitworthiness Interpretation, ${ }^{4}$ abduction is all about determining the relative pursuitworthiness of available explanatory hypotheses in order to select the most promising one for further considerations (especially for empirical tests). ${ }^{5}$ According to this interpretation, hence, abduction is a process of hypotheses-ranking. Finally, according to the third interpretation that I call the Unified Interpretation, abduction includes both hypotheses-generation and hypotheses-ranking.

I elsewhere argue that the Unified Interpretation is the best and the closest interpretation to what Peirce describes in his voluminous works on abduction (Mohammadian forthcoming; see also Delaney 1982, p. 178; 1993, p. 40; Stewart 1991). Thus, I do not argue for this claim here and in the following I only provide a detailed description of Peirce's theory of abduction according to the Unified Interpretation. In order to make it easier to follow different phases of abduction and different stages of scientific inquiry in Peirce's view, I provide a schematic figure of them (Figure 1).

According to the Unified Interpretation, abduction consists of two phases. Phase One is hypotheses-generation through which we come up with new hypotheses to explain a given

${ }^{3}$ Some advocates of the Generative Interpretation of abduction are Davis (1972, Chapter II), Hintikka (1998), Burton (2000), and Minnameier (2004).

${ }^{4}$ I borrow "the Generative Interpretation" and "the Pursuitworthiness Interpretation" from McKaughan (2008).

${ }^{5}$ Some advocates of the Pursuitworthiness Interpretation of abduction are Laudan (1980), Achinstein (1993), and McKaughan (2008). 
phenomenon. In Phase Two, these hypotheses are ranked to determine their relative pursuitworthiness for further considerations. In the following, I describe these two phases in detail.

\subsection{Phase One of Abduction: Hypotheses-Generation}

According to Peirce, abduction is the only type of inference that is "originary" $(2.96,1902)$ and "starts a new idea" $(5.145,1903)$. This is done through "forming an explanatory hypothesis" (5.171, 1903) to explain a "surprising" phenomenon that we would not have expected under particular circumstances $(2.776,1902)$. An explanation is a proposition that "would lead to the prediction of the observed facts, either as necessary consequences or at least as very probable under the circumstances" (7.202, 1901). Peirce knows very well that one can come up with as many explanations as she wishes for a given phenomenon and her explanations can be as "wild" as she wants so long as she can imagine some way in which the explanations make the explanandum a matter of course:

A physicist comes across some new phenomenon in his laboratory. How does he know but the conjunctions of the planets have something to do with it or that it is not perhaps because the dowager empress of China has at that same time a year ago chanced to pronounce some word of mystical power ... Think of what trillions of trillions of hypotheses might be made of which one only is true; $(5.172,1903$; my emphasis)

Thus, in principle, there is a very large pool of possible-to-imagine explanatory hypotheses for any surprising phenomena. However, in practice, scientists only invent a small number of explanatory hypotheses without even thinking about most of the possible-to-imagine hypotheses. In Peirce's own words "trillions of trillions of hypotheses might be made ... [but] after two or three or at the very most a dozen guesses, the physicist hits pretty nearly on the correct hypothesis" $(5.172,1903)$.

Two questions should be addressed here. First, how do scientists come up with new explanatory hypotheses? Second, why do scientists come up only with a handful of reasonable explanatory hypotheses? Peirce provides one answer for both questions: humans (but not only humans) possess a mental faculty of guessing called insight which enables them not only to guess (i.e., to generate) explanatory hypotheses, but also to generate only plausible hypotheses. In other words, insight has two functions. As the "faculty of divining the ways of Nature" $(5.173,1903)$ or the "guessing-instinct" $(6.531,1901 ; 7.46,1907)$, it performs an inventive function through hypotheses-generation. But as a tendency "toward a positive truth" (5.591, 1903), "to conjecture rightly" (7.679, 1903), or "toward preferring truthful hypotheses" (7.680, 1903), it performs a restrictive function by only inventing reasonable hypotheses. 
Peirce has several discussions on insight which constitute a large part of his theory of abduction. Emphasis on the role of insight in abduction can be seen from 1883 in "A Theory of Probable Inference" until 1913, a few months before Peirce's death, in "An Essay toward Improving Our Reasoning in Security and in Uberty.” Here I confine myself to mentioning some of its crucial characteristics for our current discussion:

- Insight is an instinct — the "guessing-instinct" (6.531, 1901; 7.46, 1907)—and as such, it is a disposition. In particular, it is the tendency "to conjecture rightly" $(7.679,1903)$ or "toward preferring truthful hypotheses" $(7.680,1903)$.

- Insight has an evolutionary value. It is not simply that without insight a human being could not obtain scientific knowledge; rather "he could not have maintained his existence for a single generation" (5.603, 1903). For many activities that were necessary for the survival of our ancestors — such as providing food and reproduction-required sound judgments about their physical environment and their fellow beings. Thus, those with good insight had a significant evolutionary advantage over those who did not have good insight and made bad guesses such as "This wooden rod is strong enough to kill a mammoth" or "I can outrun a tiger."

- Insight is alogical and arational because it does not operate through "a self-controlled and critical logic" and for this reason an inquirer "cannot give any exact reason for his best guesses" (5.173, $1903)$ and contents herself to call them "reasonable" or "plausible" $(5.174,1903 ; 5.415,1905$; $8.223,1910)$.

To sum up, generating hypotheses to explain a surprising phenomenon is the primary function of abduction's Phase One. This function is performed by a mental faculty called insight through which we invent some plausible hypotheses that potentially explain the surprising phenomenon.

\subsection{Phase Two of Abduction: Hypotheses-Ranking}

The hypotheses that are generated by insight, though plausible, are mere guesses and at best only one of them is true. In order to find out the true explanation, these hypotheses should be tested. We can randomly pick the hypotheses one by one and test them. This strategy is not reasonable though because it results in the wasting of time, money, energy, etc. Thus, Peirce argues that in order to "select that one [explanatory hypothesis] which is suitable for being tested by experiment" (NEM4: 
62, 1902), ${ }^{6}$ we should systematically rank the hypotheses to determine their priority for further examinations. This ranking "will include a preference for any one hypothesis over others which would equally explain the fact" $(6.525,1901)$. Providing this ranking to determine the relative pursuitworthiness of rival explanatory hypotheses for empirical testing constitutes Phase Two of abduction.

The criteria based on which hypotheses should be ranked are determined by what Peirce calls economy of research. Here, he uses "economy" in a broad sense, i.e., "economy of money, time, thought, and energy" $(5.600,1901$; see also 6.528, 1901; 7.600, 1903). Some of the "economic" desiderata that Peirce mentions include cost of testing, testability, intelligibility, consistency with well-confirmed beliefs $(7.220,1901)$, refutability $(1.120,1896)$, fruitfulness or ability for continuation of inquiry $(7.480,1898)$, broad scope, simplicity $(7.221,1901)$ and accuracy (W8: xli, 1890). ${ }^{7}$ Cost of testing aside, other desiderata that are mentioned here are called "theoretical virtues" or "epistemic values" in contemporary philosophy of science. It is generally accepted that these virtues make theories and hypotheses good ${ }^{8}$ and some even argue that they are truth-conducive. ${ }^{9}$ For Peirce, however, "abduction commits us to nothing. It merely causes a hypothesis to be set down upon our docket of cases to be tried" $(5.602,1903)$. Thus, having a higher rank does not make a hypothesis more likely to be true. It only means that its testing-and hence detecting whether it is true of false-requires less expenditure of time, money, energy, etc. than a lower-ranking hypothesis and hence it is worthier to pursue (NEM4: 37-8, 1902).

So after insight generates some plausible hypotheses to explain a surprising phenomenon in Phase One of abduction, Phase Two ranks these hypotheses, primarily based on their theoretical virtues, to determine their relative pursuitworthiness for further examinations. The hypothesesranking marks the end of abductive inference which, for Peirce, is the first stage of scientific inquiry. After abduction, we derive necessary and testable consequences of the highest-ranking hypothesis through deduction, which constitutes the second stage of scientific inquiry, and take them as predictions. Induction, according to Peirce, is the third and the final stage of scientific inquiry and

\footnotetext{
${ }^{6}$ References to Peirce's The New Elements of Mathematics (1976) are of the form (NEM volume number: page number, date).

${ }^{7}$ References to the eighth volumes of Writings of Charles S. Peirce: A Chronological Edition (2010) are of the form (W8: page number, date).

${ }^{8}$ See, for instance, Kuhn (1977), Quine and Ullian (1978, Chapter vi), Hempel (1979), and Laudan (1984).

9 For instance, Newton-Smith (1981, pp. 226-32), McMullin (1996), Lipton (2004, Chapter 9), and Schindler (2018).
} 
consists of testing those predictions to see whether they are true or false $(5.141,1903 ; 2.755,1902)$. In principle, by induction scientific inquiry terminates in the discovery of "the sole true explanation" (7.219) of the given phenomenon. Figure 1 provides a schematic picture of the two phases of abduction and the three stages of the scientific inquiry as described by Peirce.

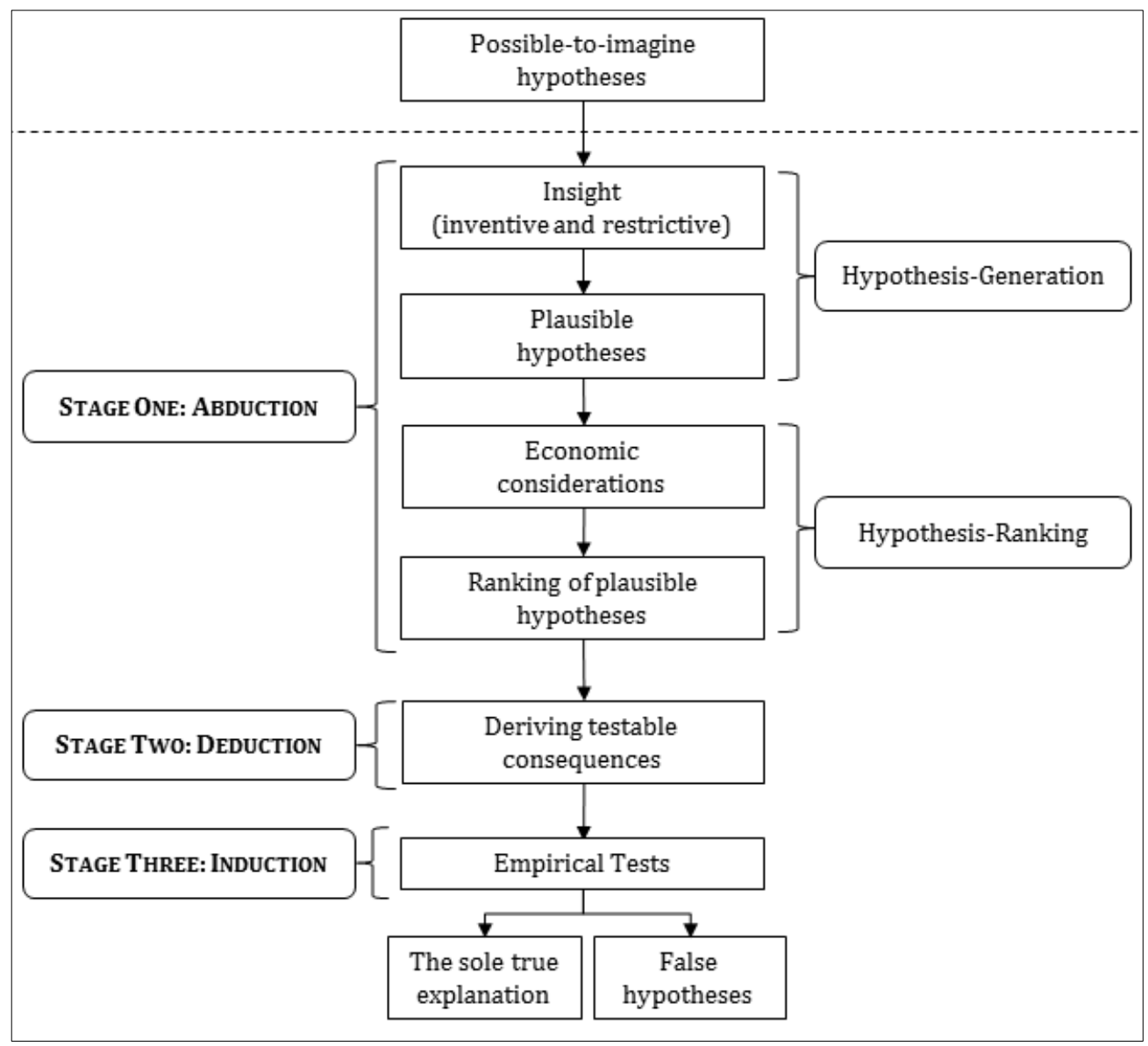

Figure 1. Peirce's Three Stages of Scientific Inquiry (above the dashed line is the realm of mere possibility and is not actually a part of scientific enquiry.)

\section{Inference to the Best Explanation}

In this section, I provide a general description of IBE. The term "Inference to the Best Explanation" was coined by Harman in 1965. Since then, it has become a term of art and sometimes philosophers use it in different ways. For instance, different accounts of IBE vary in terms of how demanding their characterization of the best explanation is. For Harman, IBE is a type of inference in which "one infers, from the premise that a given hypothesis would provide a "better" explanation for the evidence than would any other hypothesis, to the conclusion that the given hypothesis is true" (1965, p. 89). Musgrave, however, holds that it is not enough for the best explanation to be simply 
better than its rivals; rather, by itself it should be a "satisfactory" explanation too (1988, p. 239). Hacking's construal of IBE is even more demanding:

if, confronted by some phenomenon, you find one explanation (perhaps with some initial plausibility) that makes sense of what is otherwise inexplicable, then you should conclude that the explanation is probably right. (1983, p. 52, my emphasis)

In this construal, the best explanation should also be the only available explanation, the one without which the phenomenon remains unexplained.

In this paper, I do not aim to evaluate different views of IBE. So, for the purpose of our current discussion, I simply focus on Peter Lipton's (2004) account of IBE which is one of the most developed accounts in the literature to this date. In the following, I describe Lipton's IBE and in order to make it easier for the reader to follow all its different stages—and, later, to compare it with abduction-I provide its schematic depiction (Figure 2).

\subsection{Lipton's Account of IBE}

According to Lipton, in principle, IBE is an inference to the best potential explanation in a broad sense:

the potential explanations of some phenomena are those that do explain them in a possible world where our observations hold. This pool is very large, including all sorts of crazy explanations nobody would seriously consider. (Lipton 2004, p. 59, my emphasis)

Obviously, the pool of all potential candidate explanations is not an actual set of candidate explanations. After all, they are merely potential and most of them, although possible to imagine, are not even thought about. In practice, therefore, IBE always begins with a significantly smaller pool of "live options" or "plausible candidates" (Lipton 2004, p. 59) that only includes those hypotheses that are actually taken seriously by scientists for explaining a phenomenon. The process of narrowing down the pool of all potential explanations to the pool of plausible candidates is the function of what Lipton calls the "plausibility filter" (Lipton 2004, p. 61).

\subsubsection{The First Filter of IBE}

The plausibility filter is the first filter of IBE and consists of two main elements that work together. The first element is contrastive evidence. Lipton advocates a contrastive view of explanation according to which most of the times what gets explained "is not simply 'Why this?', but 'Why this rather than that?"' (2004, p. 33). Contrastive evidence is the evidence that can be used to answer the latter but not necessarily the former question and Lipton uses it as a filter to remove some merely possible explanations. 
For instance, consider Lipton's favorite example, namely, Ignaz Semmelweis's research on childbed fever in the Vienna Hospital. Although Semmelweis was looking for the cause of childbed fever, he did not simply ask "What does explain childbed fever?" Rather, he focused on a contrast that he observed between the mortality rates (caused by childbed fever) of the two maternity wards and asked: "Why the mortality rate of the first ward is higher than the mortality rate of the second ward?" A merely potential explanation could pass the plausibility filter to become a live option only if it could potentially explain this contrast in mortality rates. This enabled Semmelweis to eliminate candidate explanations such as childbed fever epidemic and diet because these factors were similar between the two wards and hence they were unable to explain the contrast in mortality rates.

For Lipton, the second element of plausibility filter is our background beliefs (2004, p. 73) which limit the number of plausible candidates in two ways. First, they help us to determine which contrasts are relevant. For instance, Semmelweis restricted his research to the contrast between the mortality rates of maternity wards and did not take into account the general division of the hospital because he knew that childbed fever happens following childbirth or miscarriage. Second, background beliefs filter those "crazy" candidates that do not cohere with them. For instance, since seeking astrological explanations is inconsistent with scientists' strong beliefs, they never consider them as live options in the first place.

\subsubsection{The Second Filter of IBE}

After narrowing down all potential explanations to plausible options using the plausibility filter, a second filter eliminates some of the plausible options and hence narrows down the pool of plausible explanations even more. This filter consists of two processes: (i) figuring out what data can discriminate against a plausible candidate explanation and (ii) producing those data via experimentation. This filter, according to Lipton, might narrow down the pool of plausible candidates to a single explanation.

For instance, in the case of Semmelweis's research, the delivery position of women in the first ward was different from women in the second ward. This made the delivery position a plausible candidate to explain the mortality rate contrasts. Semmelweis correctly reasoned that if this candidate explanation is true, changing the delivery position of women in the first ward should result in more or less similar mortality rates for both divisions. This specified the discriminating data against (or in favor of) the delivery position hypothesis. He tested the hypothesis by changing the delivery position of women in the first ward but did not observe any changes in the mortality rate. Thus, he rejected the delivery position hypothesis. Yet, Semmelweis also found out that only in the 
first ward women were exposed to "cadaveric matter" from obstetrical training of medical students. Again, he hypothesized that it might be a cause of the higher rate of childbed fever in the first ward. He asked all the students to disinfect their hands after performing autopsies. As a result, the mortality rate of the first division reduced to the same level as that of the second division. This confirmed that the cadaveric matter is a cause of childbed fever.

\subsubsection{IBE's Ranking Process}

Since Lipton calls his account "the two-filter version" of IBE (2004, p. 67) and his paradigmatic example-i.e., Semmelweis's research—is successfully finished ${ }^{10}$ after the second filter, one might imagine that there is nothing more to IBE besides the two filters. There is, however, a third stage in Lipton's IBE that he does not discuss as explicitly as the two filters. This stage addresses a "daunting question" that "cannot be avoided in a full assessment of Inference to the Best Explanation," that is, the "question of comparative loveliness ... [of] two hypotheses [that] do both explain the same data" (Lipton 2004, p. 90). Lipton acknowledges that usually the second filter narrows down the live options to a group of empirically equivalent yet different explanations. A complete account of IBE should include a procedure for selecting the best of these empirically equivalent candidates:

Typically, this process [i.e., the second filter] will not leave only one candidate in the running, but then the diverse explanatory considerations mentioned in the last chapter, considerations that include mechanism and unification, come into play. (Lipton 2004, p. 149)

The diverse explanatory considerations that Lipton mentions here are explanatory virtues of candidate explanation. Beside mechanism and unification, these "features that make one explanation lovelier than another" include "precision, scope, simplicity, fertility or fruitfulness, and fit with background belief" (Lipton 2004, p. 122). So if multiple candidate explanations pass the second filter, in the third stage we should determine their comparative loveliness. For this reason, the candidates should be ranked based on their explanatory virtues. The one with the highest-ranking is the best explanation.

To sum up, as Figure 2 depicts, Lipton's IBE begins with the plausibility filter that determines which candidate explanations are live options and should be taken seriously. Then, the

\footnotetext{
${ }^{10}$ This is not an accurate description of Semmelweis's research. Through a close historical examination of his research, Dana Tulodziecki (2013) convincingly argues that Semmelweis was not as perfect a reasoner as he is depicted by many philosophers of science-including Lipton-to be. For instance, at different stages of his research, he was simply ignoring available alternative explanations.
} 
second filter eliminates some of the plausible candidates or live options through the empirical data that is produced by new observations and experimentations. Finally, if multiple candidates pass the second filter and survive the empirical tests, a ranking process ranks these empirically equivalent explanations based on their explanatory virtues. The highest-ranking candidate is the best explanation.

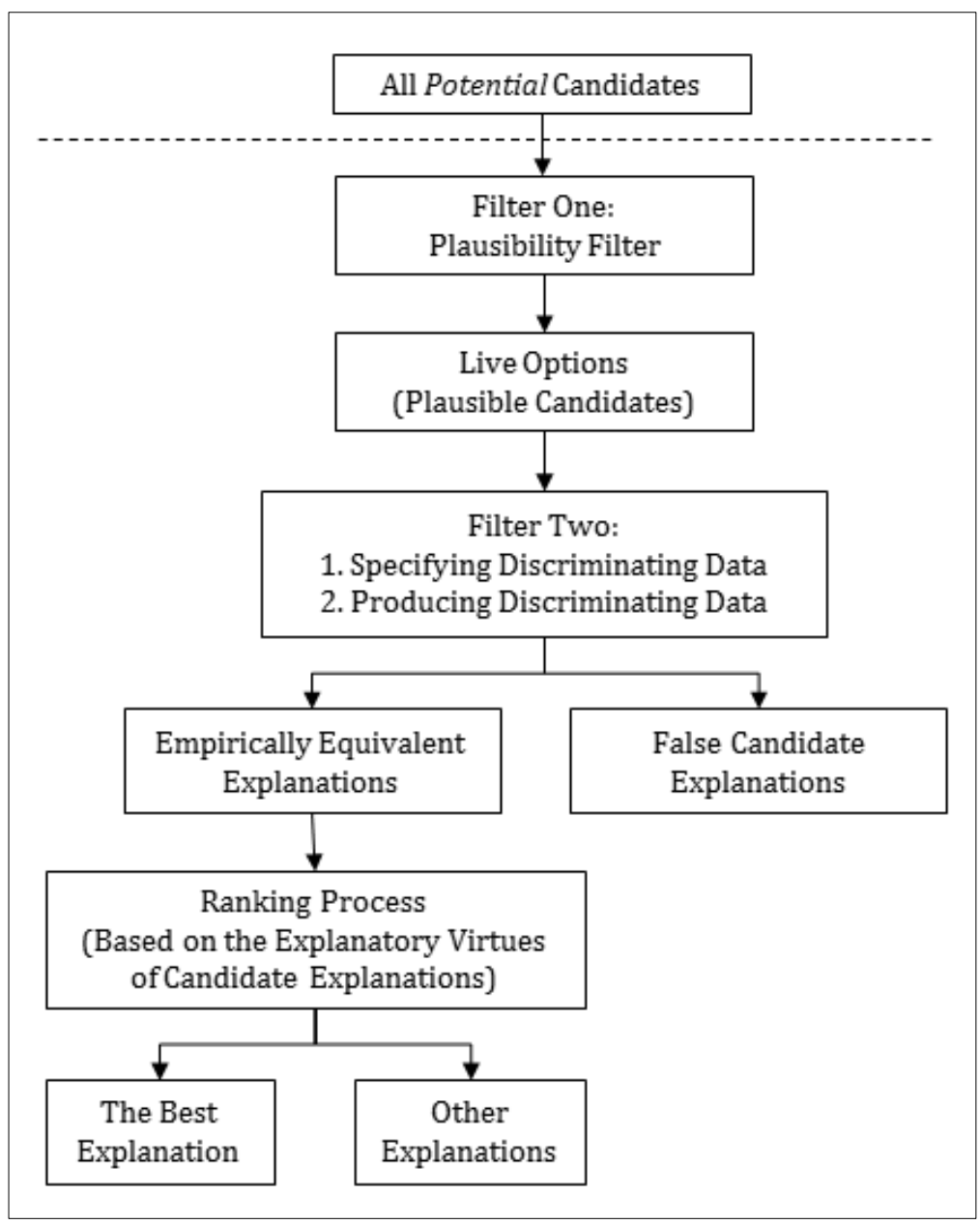

Figure 2. Lipton's account of IBE (above the dashed line is the realm of mere possibility and is not actually a part of IBE.)

\section{From Abduction to IBE}

In this section, I examine the relationship between abduction and IBE-it would be helpful for the reader to refer to Figures 1 and 2 through this comparison. I show that they have important differences and similarities. More importantly, I argue that their major differences are natural results of two historic developments in the philosophy of science, i.e., Reichenbach's DJ distinction and the problem of underdetermination of theory by data. 


\subsection{Abduction Is neither Induction nor Deduction}

First, let's briefly discuss an obvious difference between abduction and IBE. Through abduction, we come up with some explanatory hypotheses for a given phenomenon and a ranking of these hypotheses which determines their pursuitworthiness. But finding testable consequences of these hypotheses is a function of deduction, performing experiments to test them is induction, and these two types of inference are strictly distinct from abduction. Lipton, however, includes these inferences within the second filter of IBE. For, identifying discriminating data should be done deductively and producing the discriminating data via experimentation is equivalent to Peircean induction. Therefore, abduction is different from IBE because the latter includes induction and deduction. Since different versions this distinction between abduction and IBE has been already discussed in the literature, ${ }^{11}$ I do not delve into more details here. Instead, in the following, I shall focus on two differences that have not been discussed.

\subsection{Insight and the Context of Discovery}

The first major difference between abduction and IBE that I discuss here can be better seen against one of their interesting similarities. Both abduction and IBE include something to narrow down a large number of possible-to-imagine candidate explanations for a given phenomenon to a significantly smaller pool of plausible hypotheses: in abduction, insight has a restrictive function for this reason and IBE includes the plausibility filter. But insight and plausibility filter are different in a significant way. Insight is primarily the faculty of generating new hypotheses and its restrictive function is secondary and through not-inventing implausible hypotheses. The plausibility filter, however, functions restrictively; after all, it is just a filter. Neither of its elements, namely, contrastive data and background beliefs, can invent new explanatory hypothesis as insight does. This constitutes the first crucial difference between abduction and IBE: only abduction fully embraces hypothesesgeneration.

In the following, first I argue that hypotheses-generation in Peircean abduction is one of the main targets of Reichenbach's DJ distinction and its consequent jettisoning of the context of discovery from philosophy of science. Then I show that in comparison with abduction, Lipton's IBE covers the context of discovery quite minimally. In particular, there is nothing corresponding to the

\footnotetext{
${ }^{11}$ Hintikka (1998) distinguishes between abduction and IBE on the ground that the latter is more akin to deduction. Minnameier (2004), however, claims that abduction is different from IBE, because the latter is similar to Peirce's concept of induction. Campos (2009), too, extensively discusses the fact that abduction has nothing to do with confirming (or disconfirming) evidence for a hypothesis-i.e., has nothing to do with induction-while IBE is similar to induction.
} 
inventive function of insight in IBE. This can be seen as a natural result of Reichenbach's DJ distinction.

\subsubsection{Historical Link between Abduction and Reichenbach's DJ Distinction}

The astonishing historical relationship between abductive hypotheses-generation and Reichenbach's DJ distinction is neglected in the history of philosophy of science. Before shedding some light on this interesting issue, first let's begin with the well-known but less direct relationship between hypotheses-generation and the context of discovery. In his Experience and Prediction (1938a), Reichenbach uses "discovery" for the subjectively performed process of finding a new theory (1938a, pp. 5-7). In his later work, The Rise of Scientific Philosophy (1951), Reichenbach describes the context of discovery in more detail:

The scientist who discovers a theory is usually guided to his discovery by guesses; he cannot name a method by means of which he found the theory and can only say that it appeared plausible to him, that he had the right hunch, or that he saw intuitively which assumption would fit the facts [...] The act of discovery escapes logical analysis; there are no logical rules in terms of which a "discovery machine" could be constructed that would take over the creative function of the genius. (1951, pp. 230-231; my emphasis)

Now, recall the characteristics of insight that were discussed before. As we see, Reichenbach's description of the context of discovery is almost identical to Peirce's descriptions of hypothesesgeneration by insight. But Reichenbach also holds that the context of discovery is not a proper philosophical topic and hence he banishes it from philosophy of science to psychology, sociology, or history. Thus, once one adopts Reichenbach's DJ distinction, she should discard insight and hypotheses-generation from her philosophical account of explanatory inference.

But the historical link between abduction and Reichenbach's DJ distinction is more intimate and interesting. In the literature, the DJ distinction is always traced back to Reichenbach's Experience and Prediction-see, for instance, Howard (2003, p. 54, 2006), Richardson (2006), and Schickore (2018). What is overlooked by these (and many other) authors is that shortly before the publication of Experience and Prediction, the DJ distinction appears in one of Reichenbach's papers (1938b). Here is the background story of this paper.

In 1935, Reichenbach publishes his Wahrscheinlichkeitslehre ${ }^{12}$ in which he proposes a probabilistic approach to theory choice and theory confirmation in science. A year later, Nagel

\footnotetext{
12 The book was later translated into English as The Theory of Probability (1949).
} 
(1936) publishes a review of Reichenbach's book and criticizes his probabilistic approach to theory choice. He claims that not only do scientists not really talk about probabilities of theories, but also they do not even think that "the probability of a theory" has an objective meaning. He continues: eminent men of science repeatedly assert that a theory is found satisfactory by them partly on esthetic grounds, partly because they know no alternative theory, and partly because the consequences of the theory have been tested in accordance with a definite technique $[\ldots]$ it seems to me that the last suggesttion $[s i c]$, thrown out but left undeveloped by Charles $S$. Peirce, comes closer to stating the procedures actually employed in the sciences than anything that Prof. Reichenbach has indicated on this matter. (Nagel 1936, p. 508)

Obviously, in this passage Nagel does not talk about abduction. Rather, he talks about Peircean induction, i.e., "the experimental testing of a theory" $(5.145,1903)$. In response to Nagel's criticism Reichenbach writes a paper which shows that he totally misunderstands Nagel (and Peirce) in this regard. For the first time, the DJ distinction appears in this paper that is published in January 1938, several months before Experience and Prediction. Reichenbach writes:

If we want to construct a philosophy of science, we have to distinguish carefully between two kinds of context in which scientific theories may be considered. The context of discovery is to be separated from the context of justification; the former belongs to the psychology of scientific discovery, the latter alone is to be the object of the logic of science. The confusion of the two kinds of context has become the root of many a misinterpretation of the procedure of science. I confess that the remarks of Peirce concerning the construction of scientific theories, quoted against me by Dr. Nagel, seem to me to suffer from the same confusion. I admire Charles Peirce as one of the few men who saw the relations between induction and probability at an early time; but just his remarks concerning what he calls "abduction" suffer from an unfortunate obscurity which I must ascribe to his confounding the psychology of scientific discovery with the logical situation of theories in relation to observed facts. ${ }^{13}$ (1938b, p. 36, original emphasis)

I am not claiming that this was the first time that Reichenbach came up with the idea of the DJ distinction. Nor am I claiming that Peirce's theory of abduction is the only target of the DJ

\footnotetext{
${ }^{13}$ Having a high view of Peirce's theory of induction and probability and, at the same time, ignoring (if not disdaining) his theory of abduction could be seen among other philosophers too. Braithwaite (1934), for instance, claims that Peirce's theory of probability and induction is one of the most important parts of his logic but there is nothing substantial in his theory of abduction in general, and insight in particular.
} 
distinction. ${ }^{14}$ However, this passage reveals that one of the earliest targets of Reichenbach's DJ distinction is abduction and, in particular, its hypotheses-generation. This position is reinforced by the fact that in 1939, in his contribution to the first volume of the Library of Living Philosophers series on The Philosophy of John Dewey (Schilpp, 1939), Reichenbach (1939, p. 188, n. 28) once again relates Peircean abduction with the context of discovery. ${ }^{15}$

In the light of this historical fact, it becomes clear why one of the earliest and the most famous critics of Reichenbach's DJ distinction is also an advocate of Peirce's account of abductive hypotheses-generation. In Patterns of Discovery (1958), Norwood Russell Hanson writes

Disciples of the H-D [i.e., hypothetico-deductive] account often dismiss the dawning of an hypothesis as being of psychological interest only, or else claim it to be the province solely of genius and not of logic. They are wrong. If establishing an hypothesis through its predictions has a logic, so has the conceiving of an hypothesis. (1958, p. 71)

Hanson does not mention who these disciples of the hypothetico-deductive account are. But a quick look at Reichenbach's most extensive discussion about the DJ distinction clears all doubt. Reichenbach opens chapter fourteen of The Rise of Scientific Philosophy (1951) with a discussion about hypothetico-deductive method and how some philosophers have misunderstood this method by conflating it with the "psychological description of discovery" (1951, p. 230). And where does this misunderstanding come from? Reichenbach thinks that "The mystical interpretation of the hypothetico-deductive method as an irrational guessing springs from a confusion of context of discovery and context of justification" (1951, p. 231). After his clear attack on Reichenbach's DJ distinction, Hanson suggests that abduction provides us with a fruitful and promising theory of the logic of discovery (1958, Chapter IV).

In summary, I argued that from the beginning of its development, one of the main targets of Reichenbach's DJ distinction was abductive hypotheses-generation. For Reichenbach, it pertains to the context of discovery and, therefore, it is not a proper philosophical subject-matter. Now, I show that in comparison with abduction, IBE covers the context of discovery very minimally.

\subsubsection{IBE and the Context of Discovery}

Reichenbach's DJ distinction and the consequent exclusion of the context of discovery from philosophy of science became a central dogma of logical empiricist philosophy of science (Howard

\footnotetext{
${ }^{14}$ Don Howard (2006, p. 4) convincingly argues that the DJ distinction also targets the left wing of the Vienna Circle, especially Otto Neurath (1913).

${ }^{15} \mathrm{I}$ am in debt of Don Howard who brought my attention to this work.
} 
2006, p. 3). ${ }^{16}$ Hempel, for instance, adopts the same approach towards hypotheses-generation and holds that "We may leave aside ... the question of ways of discovery; i.e., the problem of how a new scientific idea arises, how a novel hypothesis or theory is first conceived” (1965a, pp. 82-83) because "the ways in which fruitful scientific guesses are arrived at are very different from any process of systematic inference" (1966, p. 205). Thus, in his hypothetico-deductive model of confirmation, Hempel completely ignores the context of discovery.

Since Lipton (2004, p. 3) introduces IBE as an alternative that compensates for the shortcomings of (Hempel's) hypothetico-deductive model, one might expect that IBE covers the context of discovery. In fact, Lipton makes such a claim but there is an important provision that should be taken into consideration. Lipton only claims that IBE covers the context of discovery better than Hempel's hypothetico-deductive model (2004, p. 82). Since Hempel completely jettisons the context of discovery from his philosophy of science in general, and his hypotheticodeductive model in particular, we should not expect too much from Lipton's IBE with respect to the context of discovery.

As mentioned before, Reichenbach and Hempel understand the context of discovery primarily-if not exclusively-in terms of the mental and psychological aspects of the thought processes that result in invention of new hypotheses. In his description of the context of discovery, Reichenbach uses phrases like "the form in which thinking processes ... are subjectively performed" (1938, p. 6), "psychological description of discovery" (1951, p. 230), and "the creative function of the genius" (1951, p. 231). Hempel's characterization of the context distinction, too, relies on the distinction between "logical and psychological issues" (1965b, p. 6). The paradigmatic example of the latter is the invention of scientific hypotheses "by an exercise of creative imagination" (2001, p. 32, original emphasis; see also: 2000, pp. 75-76,). Understood in this sense, the context of discovery is fully embraced in Peircean abduction in which the mental faculty of insight plays a significant role. Yet, the psychology of discovery and the mental and psychological aspects of the thought processes that result in invention or generation of new hypotheses are missing from Lipton's IBE to a great extent.

\footnotetext{
${ }^{16}$ The close association of the DJ distinction and the logical empiricist movement neither means that the DJ distinction did not survive the demise of logical empiricism nor that it was not accepted by philosophers unsympathetic to this movement. In fact, a precursor of the DJ distinction was introduced in the German edition of Popper's The Logic of Scientific Discovery (2002, p. 7, originally published in 1934), four years before its appearance in Reichenbach's works.
} 
The closest that Lipton gets to covering the context of discovery in IBE is when he discusses how effectively the plausibility filter-i.e., the first filter-narrows down the huge pool of possibleto-imagine candidates to the small pool of plausible candidates:

This version of Inference to the Best Explanation thus sheds some light on the context of discovery, since the requirement that a potential explanation cite a difference [i.e., the requirement of contrastive explanation in the plausibility filter] severely restricts the class of candidate hypotheses. (Lipton 2004, p. 73, my emphasis)

Lipton calls this eliminative process "the short list mechanism" through which only a very limited number of plausible hypotheses are generated in the first place (Lipton 2004, pp. 148-51). As mentioned before, Peirce explains this process by invoking the mental faculty of insight which invents only plausible hypotheses. This opens a room for a full inclusion of the context of discovery in abduction. Lipton's approach, however, is quite different. He does not talk about the psychological process of generating new hypotheses. Rather, to explain the short list mechanism, he focuses on the role of background beliefs that "serve as heuristics that guide us to new inferences, by restricting the range of actual candidates" (2004, p. 151, my emphasis). Although background beliefs are among those mental states that contribute to hypotheses-generation, their role, as Lipton acknowledges, is heuristic.

So when Lipton invokes background beliefs to answer the question of "How can it [IBE] account for the processes by which short lists are generated?" (2004, p. 149), he primarily addresses the shortness of the lists of new hypotheses rather than their generation. But the invention or generation of the new hypotheses is what the context of discovery (as understood by Reichenbach and Hempel) is all about. By bringing the heuristic role of background beliefs in generating new hypotheses to the foreground, Lipton's IBE covers the context of discovery better than Hempel's hypothetico-deductive model, in which the context of discovery is completely missing. Yet, as opposed to abduction, IBE does not include any substantial discussion about the mental faculties that might be involved in generating new hypotheses or the psychological aspects of the thought processes that result in such inventions. Therefore, in comparison with abduction, the presence of the context of discovery in IBE is very minimal.

In this section, I provided evidence to show that abductive hypotheses-generation and insight were among primary targets of Reichenbach's context distinction who considered them within the context of discovery and hence unrelated to philosophical discussions. Then I argued that there is nothing similar to insight in IBE which can be seen as a natural consequence of the DJ distinction. 


\subsection{Hypotheses-Ranking and the Problem of Underdetermination}

The second major difference between abduction and IBE can be better seen against two of their important similarities. First, both abduction and IBE include a hypotheses-ranking process. It constitutes Phase Two of abduction and in IBE it is done after the second filter to rank the hypotheses that survive empirical tests. Second, in both abduction and IBE theoretical virtues play an important role in the process of hypotheses-ranking. In abduction, theoretical virtues are introduced by Peirce as "economic" desiderata. In IBE, the ranking is done based on the candidates' explanatory virtues which are almost identical with theoretical virtues (Lipton 2004, p. 122). However, there are two significant and related differences between the ranking processes in abduction and IBE with respect to when they are done and what they rank. In abduction, hypotheses-ranking is done before conducting empirical tests and hence it ranks untested hypotheses. In IBE, however, hypotheses-ranking is done after conducting empirical tests and it ranks successfully tested hypotheses that are—at least so far-empirically equivalent.

As a result of these two differences, hypotheses-ranking processes in abduction and IBE have two completely different goals. In abduction, the goal is to determine the relative pursuitworthiness of hypotheses for further considerations such as empirical tests. For Peirce, since a hypothesis that is ranked is yet untested, whether it ends up in a higher (or a lower) rank has neither anything to do with the understanding that the hypothesis (if true) would provide nor with its probable truth. For Lipton, however, ranked hypotheses have already survived empirical tests. Thus, the aim of hypotheses-ranking is to determine which candidate is the best or the loveliest explanation, namely, which candidate (if true) provides the best understanding of the phenomenon and is most likely to be true.

In the following, I argue that the two differences between abduction's and IBE's hypothesesranking processes can be understood in terms of the problem of underdetermination, namely, the possibility of having multiple empirically equivalent explanations for a given phenomenon. First, I show that only in IBE the possibility of empirically equivalent explanations is taken into account. Secondly, I argue that Peirce did not address the problem of underdetermination because he was not aware of this problem. In particular, I argue against those who claim that Peirce knew about underdetermination but he did not address it because his pragmatism immunes his account of scientific inquiry to this problem. 


\subsubsection{Abduction, IBE, and the Possibility of Empirically Equivalent Explanations}

According to Lipton, underdetermination is an inherent characteristic of non-deductive inferences. Because of underdetermination, in these inferences "a unique solution" is not guaranteed (2004, p. 5). As a result, he holds that in IBE, typically, the process of empirical testing "will not leave only one candidate in the running" (2004, p. 149). So, as mentioned before, he includes a hypothesesranking process in IBE after empirical tests to address the problem of underdetermination: if multiple empirically equivalent candidates pass the second filter, hypotheses-ranking specifies the comparative loveliness of the candidates and thereby determines which one is the best explanation.

Yet, Peirce believes that by the end of scientific inquiry, all the hypotheses that are abductively proposed to explain a phenomenon will be rejected inductively-i.e., through empirical tests-except for "the sole true explanation" $(7.219,1901)$ of the phenomenon: "the followers of science are animated by a cheerful hope that the processes of investigation, if only pushed far enough, will give one certain solution to each question to which they apply it" $(5.407,1878$, my emphasis). But one might imagine that empirical tests alone suffice to determine the sole true explanation of a phenomenon only if one does not take underdetermination into account. If there is no underdetermination and empirical tests can always determine one true explanation, then the best function for hypotheses-ranking is determining which hypothesis should be tested first.

In summary, to address underdetermination, Lipton includes a hypotheses-ranking process for empirically equivalent candidates after empirical tests in his account of IBE. Peirce, however, overlooks underdetermination and ends his account of scientific inquiry with induction. So in his account, hypotheses-ranking is done before empirical tests to rank untested hypotheses and determine which one is better to be tested first. Therefore, the differences between hypothesesranking processes in Peirce's abduction and Lipton's IBE regarding when they are done and what they rank can be understood in terms of underdetermination and whether it is addressed or not.

\subsubsection{Peirce and Underdetermination}

Why doesn't Peirce address the problem of underdetermination? The simple answer is that he was not aware of this problem and the possibility of the existence of multiple empirically equivalent explanations for a single phenomenon. Some challenge this simple answer and suggest that Peirce was aware of underdetermination but did not need to address it because his pragmatism immunes his account of scientific inquiry to this problem. In the following, I argue that these claims are illgrounded. First, I show that the evidence for Peirce's awareness of underdetermination is 
insufficient. Second, I argue that Peirce's pragmatism does not immune his account of scientific inquiry to the problem of underdetermination.

\section{Peirce, Poincaré, and Underdetermination}

Poincaré's Science and Hypothesis (1905, French: 1902) is one of the pioneer works in which underdetermination has been recognized. Since Peirce was familiar with Poincaré's works, ${ }^{17}$ one might imagine that he knew about underdetermination too. ${ }^{18}$ A small handful of scholars have claimed that Peirce got to recognize underdetermination. But de Regt (1999) persuasively rejects their claims. Since de Regt's paper, to the best of my knowledge, only Magnus (2005) has claimed that Peirce was aware of underdetermination. He quotes only one passage from Peirce as evidence for this claim:

Poincaré would have us write down the equations of hydrodynamics and stop there. This I declare to be contrary to demonstrated principles of logic. It is an error analogous to that of agnosticism. It is a species of agnosticism, - a recommendation that a certain line of inquiry be entirely abandoned ... Let me recommend this Logical Maxim to you:

Never allow yourself to think that any definite problem is incapable of being solved to any assignable degree of perfection. (EP2: 187-8, 1903) ${ }^{19}$

Since underdetermination has no logical or empirical solution, Magnus counts this passage as Peirce's response to this problem and hence as evidence for its recognition by him.

But there are several problems with this claim. First, the scope of the Peirce's Logical Maxim is considerably broader than underdetermination. For instance, it can be considered as a maxim against global or local skepticism. The example that Peirce provides immediately after the quoted passage is also totally unrelated to underdetermination:

Think of Auguste Comte who when asked to name any thing that could never be found out instanced the chemical composition of the fixed stars; and almost before his book became known to the world at large, the first steps had been taken in spectral analysis. (EP2: 188, 1903)

\footnotetext{
${ }^{17}$ In his works, Peirce mentions Poincaré's name and views several times $(5.495-7,1906 ; 6.370,1902)$.

${ }^{18}$ To the best of my knowledge, there is no evidence suggesting that Peirce was familiar with Pierre Duhem or his The Aim and Structure of Physical Theory (1954, French: 1906) which is considered by many as the locus classicus of underdetermination.

${ }^{19}$ References to The Essential Peirce: Selected Philosophical Writings (Peirce 1998) are of the form (EP volume number: page number, date).
} 
Therefore, more evidence is required to show that Peirce's target is indeed Poincaré's underdetermination.

Second, Poincaré's classic underdetermination thesis pertains to the geometry of physical space. In particular, Poincaré (1905, Chapter 5) claims that whether the geometry of physical space is Euclidean or non-Euclidean is underdetermined by empirical evidence produced, for instance, by measuring the sum of the angles of a physical triangle in a cosmic scale. Peirce was familiar with nonEuclidean geometries and the possibility that they might be the geometry of physical space. ${ }^{20}$ However, neither in the quoted passage nor anywhere else he discusses Poincaré's underdetermination of the geometry of physical space by empirical data. This suggests that he was not aware of Poincaré's underdetermination thesis.

Finally, the passage quoted by Magnus can hardly have anything to do with Poincarés underdetermination thesis. First, Poincaré does not fall into agnosticism which is condemned by Peirce in the passage. Rather, he explicitly endorses Euclidian geometry. Secondly, Poincaré's reason for this endorsement is that Euclidian geometry is simpler than non-Euclidian geometries (Poincaré 1905, p. 50). This is perfectly compatible with Peirce's views. He holds that of two untested hypotheses that are otherwise equivalent, the one that is simpler should be selected as the working hypothesis $(7.220,1901)$. So if there is no empirical evidence against the hypothesis that the geometry of physical space is Euclidian—as follows from Poincaré's underdetermination thesis—for Peirce it is justified to select it as the working hypothesis-as Poincaré does. Therefore, I think Magnus does not provide sufficient evidence for Peirce's awareness of underdetermination through Poincaré's works.

\section{Pragmatic Maxim and Illusionary Disputes}

Does Peirce's pragmatism make his theory of scientific inquiry immune to the problem of underdetermination? One of the kernels of Peirce's philosophy is his pragmatic maxim, famously stated in "How to Make Our Ideas Clear":

Consider what effects, that might conceivably have practical bearings, we conceive the object of our conception to have. Then, our conception of these effects is the whole of our conception of the object. $(5.402,1878)$

\footnotetext{
${ }^{20}$ Peirce wrote a review on the English translation of Lobatchewsky's Geometrical Researches on the Theory of Parallels (1891) in which he acknowledges that Lobatchewsky's geometry "may, for all we can yet observe, be the system of nature" (W8: 217, 1892).
} 
This maxim is mostly known as a criterion of meaning according to which the meaning of a proposition (or concept) is known when its effects on us are known. But the pragmatic maxim also functions as a tool of inquiry by, inter alia, detecting illusionary disputes: if two 'allegedly' different claims have no different "conceived sensible effects" $(5.401,1878)$, they are not really different and a dispute between them is illusionary. Now, since there is no disagreement between theories that are underdetermined by data vis-à-vis the conceived empirical evidence, a dispute between these theories is not genuine. That is, for Peirce, the problem of underdetermination is an illusionary dispute (French 1989, p. 298) and even if he knew about this problem, his pragmatic maxim would resolve it.

This claim is problematic for two reasons. First we it ignores all the later developments in Peirce's understanding of the pragmatic maxim. Secondly, it adopts an extremely narrow notion of "sensible effects." Let's begin with the first problem. Peirce made important revisions to his pragmatic maxim the scope of which goes well beyond this paper. So here I only content myself to one revision that has direct consequences for our discussion on underdetermination. ${ }^{21}$ The early pragmatic maxim (i.e., the 1878 version that was quoted earlier) limits the meaning of a concept only to its conceived sensible and practical bearings, that is, only to the effects that have been actually experienced. For instance, the meaning of "hard" is exhausted by all the hard objects of which we have actual experiences. Thus, according to Peirce, a diamond that is crystallized "in the midst of a cushion of soft cotton, and should remain there until it was finally burned up" $(5.403,1878)$ without anyone ever experiencing its hardness does not contribute to the meaning of "hard."

Later, however, Peirce recants restricting the meaning of a concept to its actually experienced effects. For instance, going back to the example of the untouched diamond, Peirce writes:

the question is, not what did happen, but whether it may have been well to engage in any line of conduct whose successful issue depended on whether that diamond would resist an attempt to scratch it. $(2.453,1905)$

So even an actually untouched diamond can contribute to the meaning of "hard," because it would resist an attempt to scratch it. Thus, the meaning of a concept is exhausted by the upshot of all the possible relevant experiences and not just actual experiences.

What does this revision to the pragmatic maxim have to do with the problem of underdetermination? According to the early pragmatic maxim, two underdetermined theories are

${ }^{21}$ For great discussions about Peirce's revisions to his early pragmatic maxim, see Misak (2004, pp. 2-5) and Atkin (2016, Chapter 2). In my following discussion, I heavily draw on these works, especially on Atkin's. 
indeed the same because the actual empirical data cannot make a distinction between them. According to the later pragmatic maxim, however, such theories are the same only if actual and possible empirical data can make no distinction between them. This new condition makes Peirce' pragmatism vulnerable to transient underdetermination, i.e., underdetermination of theory by the actual evidence that we currently have. For the tie between empirically equivalent theories in transient underdetermination can be break by potential evidence that is currently unavailable.

Second, the early pragmatic maxim would resolve the problem of underdetermination only if we have an extremely narrow understanding of "theories' sensible effects on us" and "theories' sensible practical bearings" such that they pertain exclusively to theories' relationship with empirical evidence. Based upon this narrow understanding, if two theories have identical relationships with empirical data, the early pragmatic maxim renders their disagreement illusionary. Yet, if we understand "theories' sensible effects on us" and "theories' sensible practical bearings" in a broader sense such that practical bearings of theories go beyond their relationships with empirical evidence, it is possible for two empirically equivalent theories to have genuine disagreements. For Peirce, however, there are at least two ways for the practical implications of scientific theories to go beyond their relationships with empirical evidence.

First, two empirically equivalent theories might be different vis-à-vis other important considerations, such as simplicity, scope of application, consistency with well-established theories, ad hocness, etc. In other words, two empirically equivalent theories might not have similar theoretical virtues. Considering the importance of these desiderata for Peirce, it is safe to say that if two scientists come up with two theories with different theoretical virtues, Peirce would not consider their dispute over whose theory is better illusionary just because their theories are empirically equivalent.

Another way that practical effects of theories go beyond their relationship with empirical evidence pertains to non-epistemic ramifications of theories. For instance, two theories that are underdetermined by data might have different economic (in its 'narrow' sense) and technological implications. Such aspects of scientific research are greatly important for Peirce. For instance, he thinks that

Researches for which men have been trained, instruments procured, and a plant established, should be continued while those conditions subsist. But the new money should mainly go to opening up new fields; because new fields will probably be more profitable, and, at any rate, will be profitable longer. (NEM4: 29, 1902) 
Similarly, as "a maxim of the economy of research", he suggests that "great encouragement should be given to applications of sciences" such as thermodynamics and electricity because of their "extreme utility" (NEM4: 63, 1902). Now, imagine that two scientists come up with two empirically equivalent theories even with similar theoretical virtues. If one theory scores better in economic or technological consideration, for instance, if it opens the door for a new technological advancement that might bring about financial profit, Peirce would not deem the dispute over which theory should be selected illusionary. ${ }^{22}$ Therefore, Peirce's pragmatic maxim does not immune his account of scientific inquiry to the problem of underdetermination.

\section{Conclusion}

My examination of the relationship between abduction and IBE showed that they are neither completely different nor identical. I argued that they have some important similarities such as (1) including a procedure to narrow down the pool of all possible-to-imagine explanations for a given phenomenon to plausible potential explanations, (2) including a hypotheses-ranking process, and (3) ranking explanatory hypotheses based on similar desiderata. They also have two important differences. First, only abduction includes a faculty for hypotheses-generation. Second, in abduction, hypotheses-ranking is done before conducting empirical tests and hence untested hypotheses are ranked through this process. But, in IBE, hypotheses-ranking is done after conducting empirical tests and the objects of ranking are empirically equivalent hypotheses that survive the tests.

Moreover, by providing a historical link between abduction and IBE, I showed that two momentous developments in philosophy of science-i.e., Reichenbach's DJ distinction and the problem of underdetermination — can make perfect sense of the abovementioned differences between abduction and IBE. That IBE—as opposed to abduction—does not include hypotheses-generation is a result of DJ distinction and banishing the context of discovery from philosophy of science. And hypotheses-ranking in abduction is before empirical tests because Peirce was not aware of the problem of underdetermination and the possibility of empirically equivalent explanations. To wit, when we remove the context of discovery from abduction and take underdetermination into consideration, we come up with IBE. To put it in a formulaic style:

Abduction - the Context of Discovery + Underdetermination $=\mathrm{IBE}$

\footnotetext{
${ }^{22}$ I do not suggest that Peirce values "applies science" more than "pure science." Quite conversely, he thinks that the latter is more valuable than the former. In fact, he encourages investment in applied sciences, because they make a great profit so we can spend more money on pure science (NEM4: 63, 1902). I just want to make it clear that Peirce cares about the economic aspects of scientific research.
} 


\section{References}

Achinstein, P. (1993). How to defend a theory without testing it: Niles Bohr and the "logic of pursuit." Midwest Studies in Philosophy, 18(1), 90-120.

Atkin, A. (2016). Peirce. London: Routledge.

Barnes, E. (1995). Inference to the loveliest explanation. Synthese, 103(2), 251-277.

Braithwaite, R. B. (1934). Review of Collected Papers of Charles Sanders Peirce (vol. I-IV). Mind, 43(172), 487-511.

Burton, R. G. (2000). The problems of control in abduction. Transactions of the Charles S. Peirce Society, 36(1), 149.

Campos, D. G. (2009). On the distinction between Peirce's abduction and Lipton's Inference to the Best Explanation. Synthese, 180(3), 419-442.

Davis, W. H. (1972). Peirce's epistemology. The Hague: Nijhoff.

de Regt, H. C. D. G. (1999). Peirce's pragmatism, scientific realism, and the problem of underdetermination. Transactions of the Charles S. Peirce Society, 35(2), 374-397.

Delaney, C. F. (1982). Peirce on "Simplicity" and the conditions of the possibility of science. In J. D. Collins \& L. J. Thro (Eds.), History of philosophy in the making: a symposium of essays to honor Professor James D. Collins on his 65th birthday (pp. 177-194). Washington, D.C: University Press of America.

Delaney, C. F. (1993). Science, knowledge, and mind: a study in the philosophy of C.S. Peirce. Notre Dame: University of Notre Dame Press.

Duhem, P. (1954). The aim and structure of physical theory. Princeton: Princeton University Press.

Fann, K. T. (1970). Peirce's theory of abduction. The Hague: Martinus Nijhoff.

French, S. (1989). A Peircean response to the realist-empiricist debate. Transactions of the Charles $S$. Peirce Society, 25(3), 293-307.

Hacking, I. (1983). Representing and intervening: introductory topics in the philosophy of natural science. Cambridge: Cambridge University Press.

Hanson, N. R. (1958). Patterns of discovery: an inquiry into the conceptual foundations of science. Cambridge: Cambridge University Press.

Harman, G. (1965). The Inference to the Best Explanation. The Philosophical Review, 74(1), 88-95.

Hempel, C. G. (1965a). Science and human values. In Aspects of scientific explanation and other essays in the philosophy of science (pp. 81-96). New York: The Free Press.

Hempel, C. G. (1965b). Studies in the logic of confirmation. In Aspects of scientific explanation and other essays in the philosophy of science (pp. 3-46). New York: The Free Press.

Hempel, C. G. (1966). Philosophy of natural science. Upper Saddle River, NJ: Prentice-Hall.

Hempel, C. G. (1966/2001). Recent Problems of Induction. In J. H. Fetzer (Ed.), The philosophy of Carl G. Hempel: studies in science, explanation, and rationality (pp. 29-48). New York: Oxford University Press.

Hempel, C. G. (1979). Scientific rationality: analytic vs. pragmatic perspectives. In T. S. Geraets (Ed.), Rationality to-day/la rationalite ajiourd'hui (pp. 46-58). Ottawa: The University of Ottawa Press.

Hempel, C. G. (1990/2000). The irrelevance of the concept of truth for the critical appraisal of scientific theories. In R. Jeffrey (Ed.), Selected philosophical essays (pp. 75-84). Cambridge: Cambridge University Press.

Hintikka, J. (1998). What is abduction? The fundamental problem of contemporary epistemology. Transactions of the Charles S. Peirce Society, 34(3), 503. 
Howard, D. (2003). Two left turns make a right: on the curious political career of North American philosophy of science at midcentury. In Logical empiricism in North America (pp. 25-93). Minneapolis: University of Minnesota Press.

Howard, D. (2006). Lost wanderers in the forest of knowledge: some thoughts on the discoveryjustification distinction. In J. Schickore \& F. Steinle (Eds.), Revisiting discovery and justification: historical and philosophical perspectives on the context distinction (pp. 3-22). Dordrecht, The Netherlands: Springer.

Kuhn, T. S. (1977). Objectivity, value judgment, and theory choice. In The essential tension: selected studies in scientific tradition and change (pp. 320-339). Chicago: University of Chicago Press.

Laudan, L. (1980). Why was the logic of discovery abandoned? In Scientific discovery, logic, and rationality (pp. 173-183). Dordrecht, The Netherlands: Springer. Accessed 17 February 2018

Laudan, L. (1984). Science and values: the aims of science and their role in scientific debate. Berkeley: University of California Press.

Levi, I. (1995). Induction according to Peirce. In K. L. Ketner (Ed.), Peirce and contemporary thought: philosophical inquiries (pp. 59-93). New York: Fordham University Press.

Lipton, P. (1991). Inference to the Best Explanation. London: Routledge.

Lipton, P. (2004). Inference to the Best Explanation (2nd ed.). London: Routledge.

Magnus, P. D. (2005). Peirce: underdetermination, agnosticism, and related mistakes. Inquiry, $48(1), 26-37$.

McAuliffe, W. H. B. (2015). How did abduction get confused with Inference to the Best Explanation? Transactions of the Charles S. Peirce Society, 51(3), 300-319.

McKaughan, D. J. (2008). From ugly duckling to swan: C. S. Peirce, abduction, and the pursuit of scientific theories. Transactions of the Charles S. Peirce Society, 44(3), 446-468.

McMullin, E. (1996). Epistemic virtue and theory appraisal. In I. Douven \& L. Horsten (Eds.), Realism in the sciences (pp. 13-34). Leuven, Belgium: Leuven University Press.

Minnameier, G. (2004). Peirce-suit of truth - why Inference to the Best Explanation and abduction ought not to be confused. Erkenntnis, 60(1), 75-105.

Misak, C. (2004). Charles Sanders Peirce (1839-1914). In C. Misak (Ed.), The Cambridge companion to Peirce (pp. 1-26). Cambridge: Cambridge University Press. Accessed 1 June 2018

Mohammadian, M. (forthcoming). Beyond the instinct-inference dichotomy: a unified interpretation of Peirce's theory of abduction. Transactions of the Charles S. Peirce Society.

Musgrave, A. (1988). The ultimate argument for scientific realism. In R. Nola (Ed.), Relativism and realism in science (pp. 229-252). Dordrecht: Springer. Accessed 15 November 2018

Nagel, E. (1936). Review of Wahrscheinlichkeitslehre. Mind, 45(180), 501-514.

Neurath, O. (1913). The lost wanderers of Descartes and the auxiliary motive (on the psychology of decision). In R. S. Cohen \& M. Neurath (Eds.), Philosophical papers 1913-1946 (pp. 1-12). Dordrecht: Springer Netherlands. Accessed 19 November 2018

Newton-Smith, W. H. (1981). The rationality of science. London: Routledge.

Paavola, S. (2006). Hansonian and Harmanian abduction as models of discovery. International Studies in the Philosophy of Science, 20(1), 93-108.

Peirce, C. S. (1931-1935). Collected papers of Charles Sanders Peirce. (C. Harteshorne \& P. Weiss, Eds.) (Vols. 1-8, Vol. 1-6). Cambridge, MA: Harvard University Press.

Peirce, C. S. (1958). Collected papers of Charles Sanders Peirce. (A. W. Burks, Ed.) (Vols. 1-8, Vol. 78). Cambridge, MA: Harvard University Press. 
Peirce, C. S. (1976). The new elements of mathematics. (C. Eisele, Ed.) (Vols. 1-4, Vol. 4). The Hague: Mouton. (Abbreviated NEM.)

Peirce, C. S. (1998). The essential Peirce: selected philosophical writings (Vols. 1-2, Vol. 2). Bloomington: Indiana University Press. (Abbreviated EP2.)

Peirce, C. S. (2010). Writings of Charles S. Peirce: a chronological edition, volume 8: 1890-1892. Bloomington: Indiana University Press. (Abbreviated W8.)

Poincaré, H. (1905). Science and hypothesis. London: Walter Scott Publishing.

Popper, K. (2002). The logic of scientific discovery. London: Routledge.

Quine, W. V., \& Ullian, J. S. (1978). The web of belief (2nd ed.). New York: McGraw-Hill.

Reichenbach, H. (1938a). Experience and prediction: an analysis of the foundations and the structure of knowledge. Chicago: University of Chicago Press.

Reichenbach, H. (1938b). On probability and induction. Philosophy of Science, 5(1), 21-45.

Reichenbach, H. (1939). Dewey's theory of science. In P. A. Schilpp (Ed.), The philosophy of John Dewey (pp. 159-92). Chicago: Northwestern University Press.

Reichenbach, H. (1949). The theory of probability: an inquiry into the logical and mathematical foundations of the calculus of probability. Berkeley: University of California Press.

Reichenbach, H. (1951). The rise of scientific philosophy. Berkeley: University of California Press.

Richardson, A. W. (2006). Freedom in a scientific society: reading the context of Reichenbach's contexts. In J. Schickore \& F. Steinle (Eds.), Revisiting discovery and justification: historical and philosophical perspectives on the context distinction (pp. 41-54). Dordrecht, The Netherlands: Springer.

Schickore, J. (2018). Scientific discovery. In E. N. Zalta (Ed.), The Stanford Encyclopedia of Philosophy. https://plato.stanford.edu/archives/sum2018/entries/scientific-discovery/. Accessed 17 November 2018

Schilpp, P. A. (Ed.). (1939). The philosophy of John Dewey. Chicago: Northwestern University.

Schindler, S. (2018). Theoretical virtues in science: uncovering reality through theory. Cambridge: Cambridge University Press.

Stewart, W. C. (1991). Social and economic aspects of Peirce's conception of science. Transactions of the Charles S. Peirce Society, 27(4), 501-526.

Tulodziecki, D. (2013). Shattering the myth of Semmelweis. Philosophy of Science, 80(5), 10651075. 